\title{
Reduced El Niño-Southern Oscillation during the Last Glacial Maximum
}

\author{
Heather L. Ford, ${ }^{1,2 *}$ A. Christina Ravelo, ${ }^{1}$ Pratigya J. Polissar ${ }^{2}$
}

EI Niño-Southern Oscillation (ENSO) is a major source of global interannual variability, but its response to climate change is uncertain. Paleoclimate records from the Last Glacial Maximum (LGM) provide insight into ENSO behavior when global boundary conditions (ice sheet extent, atmospheric partial pressure of $\mathrm{CO}_{2}$ ) were different from those today. In this work, we reconstruct LGM temperature variability at equatorial Pacific sites using measurements of individual planktonic foraminifera shells. A deep equatorial thermocline altered the dynamics in the eastern equatorial cold tongue, resulting in reduced ENSO variability during the LGM compared to the Late Holocene. These results suggest that ENSO was not tied directly to the east-west temperature gradient, as previously suggested. Rather, the thermocline of the eastern equatorial Pacific played a decisive role in the ENSO response to LGM climate.

\section{T}

he equatorial Pacific mean climate state (average oceanic and atmospheric properties across the basin) is characterized by a strong east-west sea surface temperature (SST) gradient that is tightly coupled to the thermocline and the winds that drive warm water to the west and cause cold water to upwell in the east (1). Because wind strength and the zonal SST gradient are mutually dependent, perturbations in this ocean-atmosphere link initiate and propagate El Niño-Southern Oscillation (ENSO) events (2). Theoretical and modeling studies suggest that the mean state should strongly affect ENSO (3-5) by altering the balance of several positive and negative ocean-atmosphere feedbacks that determine ENSO behavior (2, 3, 6, 7). However, climate models disagree on how these feedbacks interact when the mean state changes (8). Here we examine climate variability during the Last Glacial Maximum (LGM) ( 20,000 years ago) as an opportunity to investigate ENSO behavior during an altered mean state when ice sheets covered North America and partial pressure of $\mathrm{CO}_{2}\left(P_{\mathrm{CO}_{2}}\right)$ levels were $\sim 100$ parts per million lower than during preindustrial times (9).

We use deep-sea sediment samples from Ocean Drilling Program (ODP) site 806 in the western equatorial Pacific (WEP) warm pool and ODP site 849 in the eastern equatorial Pacific (EEP) cold tongue to examine tropical variability during discrete time intervals (Fig. 1). Site 806 is located in the heart of the warm pool on the equator, where SST variability is small and primarily at interannual-to-decadal frequencies. In contrast, site 849 is located in the EEP cold tongue extension, where variability is large and dominated equally by seasonal and canonical ENSO frequencies (2). Here we use the distribution of $\mathrm{Mg} / \mathrm{Ca}$ based temperatures measured on individual shells of surface- (Globigerinoides sacculifer) and subsurface-dwelling (Globorotalia tumida) forami-

${ }^{1}$ Ocean Sciences Department, University of California, Santa Cruz, CA 95064, USA. Biology and Paleo Environment, Lamont-Doherty Earth Observatory, Palisades, NY 10964, USA *Corresponding author. E-mail: hford@Ideo.columbia.edu nifera in a sediment sample to quantify tropical variability during the late Holocene $(<6000$ years ago) and LGM. This distribution has been used to accurately reconstruct the mean and seasonal variability at several locations, and our sample size (40 to 70 individuals) is sufficient to capture climate variability at our study sites (10). Three prior individual foraminifera studies of the LGM suggest either increased [site V21-30 (11); site CD38-17P (12)] or decreased [site MD02-2529 (13)] ENSO variability compared with the late Holocene. We synthesized these apparently di-
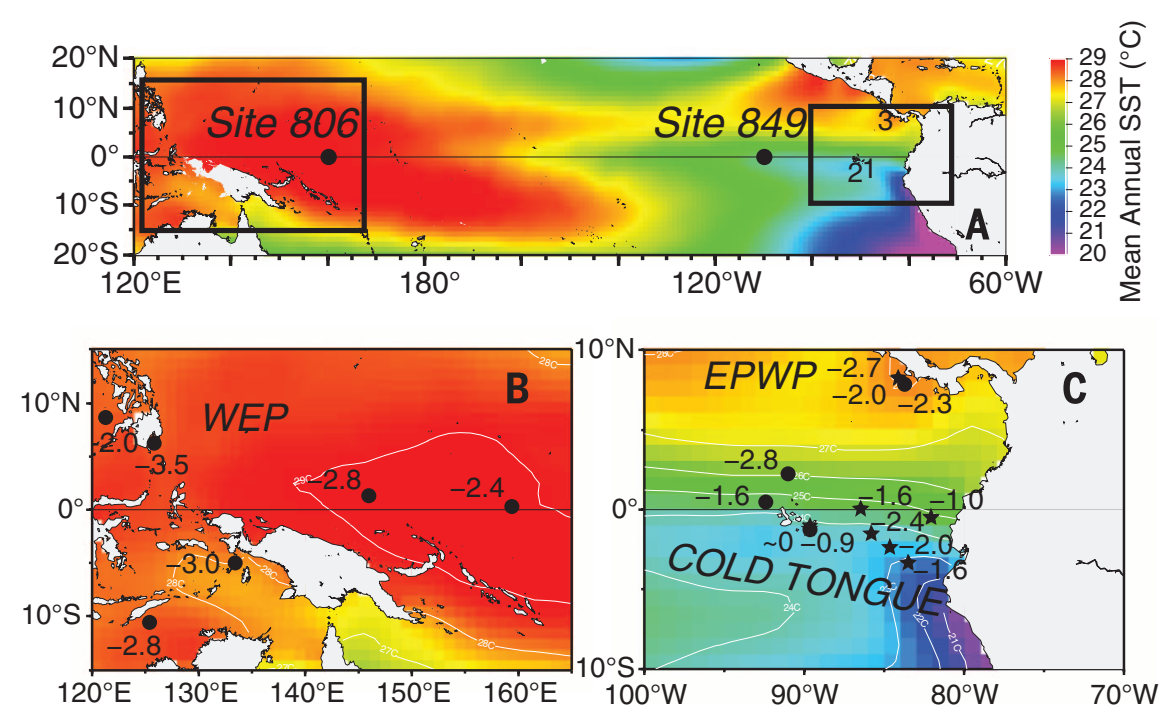

Fig. 1. Reconstruction of the zonal Holocene-LGM temperature gradient. (A) Ocean Drilling Program sites 806 and 849 indicated on a mean annual SST map, using the Met Office Hadley Centre's HadISST 1.1 data set (32). Numbers indicate individual foraminifera study sites: V21-30 (1), CD38-17P (2), and MD022529 (3). Inset maps of (B) WEP and (C) EEP show anomaly of published LGM [18 to 20 thousand years ago (ka)] minus Holocene (4 to $6 \mathrm{ka}$ ) temperatures reconstructing the zonal SST gradient. Locations using $\mathrm{Mg} / \mathrm{Ca}$ proxy are denoted by circles, whereas locations using the alkenone proxy are denoted with stars. Generally, there was a reduced zonal temperature across the Pacific, though there is some spatial heterogeneity in the EEP. The WEP and EPWP have similar cooling magnitudes $\left(\sim 2.7^{\circ}\right.$ and $\sim 2.3^{\circ} \mathrm{C}$, respectively), which suggests that LGM cooling was largely dominated by radiative cooling. In contrast, the EEP cold tongue region cooled less $\left(-1.6^{\circ} \mathrm{C}\right)$ during the LGM, indicating that radiative cooling was partially compensated by dynamic components (a deep thermocline and reduced upwelling). 
as a colder or shallower thermocline (17). However, because modeling (18), faunal (19), and geochemical (20) studies suggest that the thermocline was actually deeper during the LGM in comparison with today, our cool subsurface temperatures indicate a colder thermocline. Equatorial thermocline waters originate in mid-latitude regions where they subduct, move equatorward, and upwell along the equator (21). Our G. tumida subsurface temperatures suggest that these midlatitude thermocline source water regions were cooler during the LGM, also probably as a response to $\mathrm{PCO}_{2}$ forcing. Surface and subsurface cooling in the WEP occurred without changes in variability, consistent with $\mathrm{PCO}_{2}$ radiative forcing as the most likely agent of WEP temperature change (16).

In the EEP, our data from site 849 show that average surface temperatures were only $\sim 1.2^{\circ}$ to $1.3^{\circ} \mathrm{C}$ cooler during the LGM compared with the Holocene and that SST variability was reduced such that the cooling was greater during the warm season and smaller during the cold season (Fig. 4). Given the sensitivity of our site to ENSO, this reduction in surface ocean variability during the LGM reflects greatly reduced ENSO amplitude (Figs. 2C and 4, B and C). In contrast, site V21-30 located $\sim 2200 \mathrm{~km}$ to the east (Fig. 1) shows high surface ocean variability during the LGM, as recorded by the distribution of $\delta^{18} \mathrm{O}$ values of individual surface dwelling foraminifera (Globigerinoides ruber). An increase in variance has been interpreted as enhanced ENSO (11); however, a recent statistical study (22) suggests that the geographical location of site V21-30 is unlikely to capture changes in ENSO, and our Q-Q reanalysis of these data (fig. S13) suggests that the high variance reported at V21-30 (11) reflects enhanced seasonality during the LGM in comparison to the late Holocene. Together, these data indicate that ENSO was reduced and seasonality was enhanced during the LGM in comparison with today, which is corroborated by a recent modeling study (23). Some climate models indicate a strong inverse relationship between the amplitude of the seasonal cycle and ENSO (3); that is, when the seasonal cycle is strong, ENSO is weak. Our interpretation suggests that this inverse relationship may be a robust behavior over long time scales.

The EEP G. tumida subsurface temperatures exhibit no change in mean temperature but do show an increase in variability (Fig. 4). Although an increase in thermocline variability is consistent with enhanced ENSO (Fig. 2E), this signal is conflated with a deepening of the EEP cold tongue thermocline during the LGM $(24,25)$. Deepening of the thermocline probably led G. tumida to inhabit a shallower portion of the thermocline with a steeper temperature gradient $(24,25)$, resulting in increased reconstructed temperature variability during the LGM that obscures any true change in thermocline variability. Additionally, the lack of cooling in the LGM subsurface G. tumida measurements is consistent with this interpretation, as calcification in upper, warmer thermocline waters would offset LGM cooling. A long-term change in the depth habitat of G. tumida is unlikely because in the modern ocean it calcifies at a relatively constant depth range, regardless of vertical temperature gra-
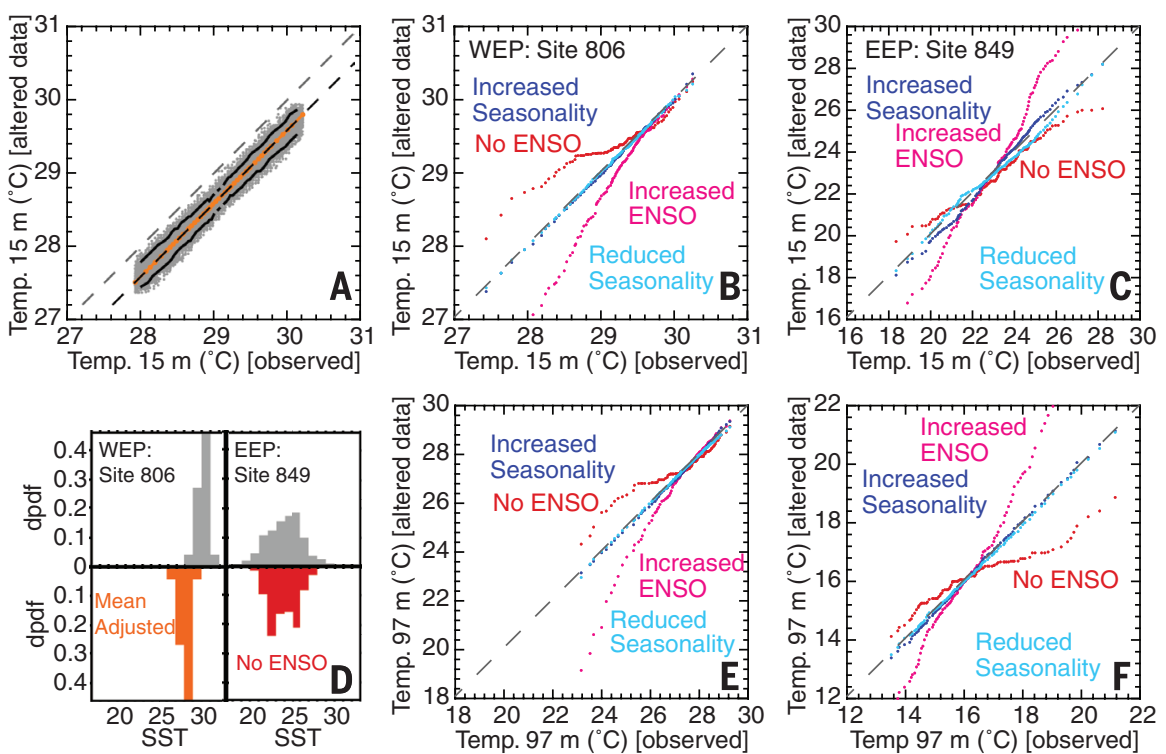

Fig. 2. Schematic framework for the interpretation of Q-Q plots of WEP (site 806) and EEP (site 849) surface and subsurface temperature variability reconstructed from planktonic foraminifera. (A) Example of a mean shift in temperature without a change in variability, as seen in a Q-Q plot. Cumulative distribution function (orange line), 1:1 line (gray dashed line), mean adjusted 1:1 line (black dashed line), Monte Carlo simulation (gray dots), and $90 \%$ confidence limits (black lines) are shown (see supplementary materials for further details). For WEP site 806 (B and $\mathbf{E}$ ) and EEP site 849 (C and F), SODA v2.4 monthly temperature data at 15 and $97 \mathrm{~m}$ are altered with no ENSO (red), increased ENSO (pink), increased seasonality (blue), and reduced seasonality (light blue). (D) Example discrete probability density function (dpdf) for unaltered data (grey), altered mean [plotted in (A), orange], and altered "No ENSO" scenario [plotted in (C), red]. dients (26). Although subsurface variability is a strong indicator of ENSO in today's ocean $(6,7)$, comparing the magnitude of subsurface variability from foraminifera proxies may not be the best indicator of ENSO strength when there are substantial changes in thermocline depth.

At site CD38-17P (east of site 849 and south of V21-30) (Fig. 1), Neogloboquadrina dutertrei show no change in mean temperature but greater subsurface temperature variability during the LGM in comparison with the Late Holocene (12). The lack of a change in mean temperature agrees with our G. tumida observation, and we similarly suggest that $N$. dutertrei must have also occupied a shallower portion of the thermocline during the LGM in comparison to today. This change in habitat explains the apparent increase in variability, and consequently, $N$. dutertrei from site CD38-17P do not support increased ENSO variability during the LGM (figs. S14 and S15).
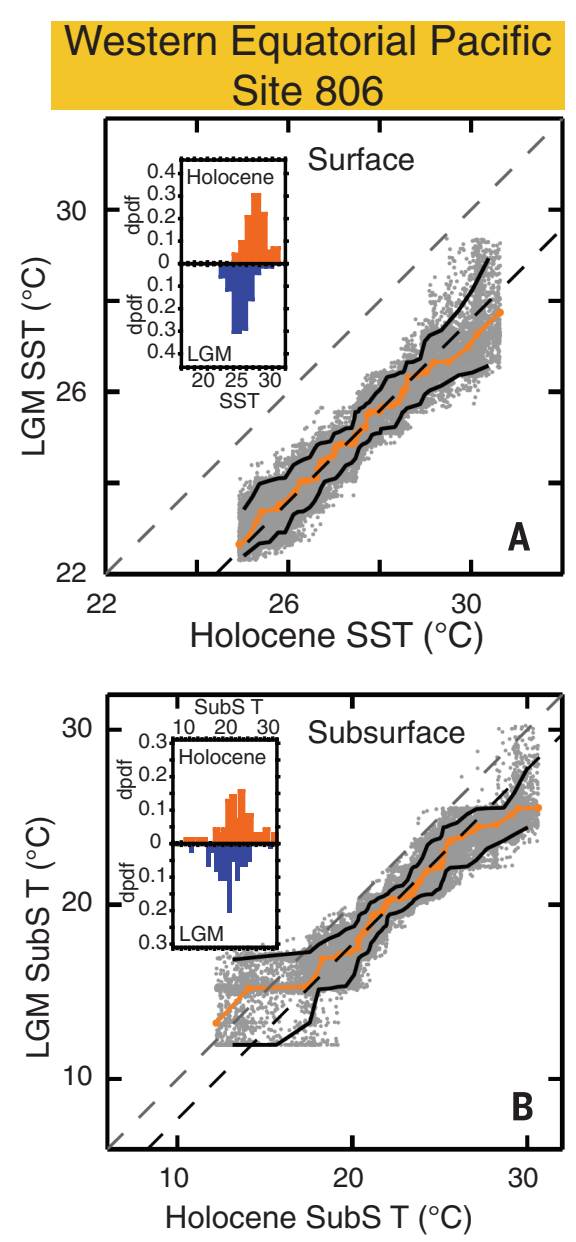

Fig. 3. Q-Q plots of WEP temperature variability reconstructed from planktonic foraminifera. (A) Surface temperature variability. (B) Subsurface temperature variability. The inset within each Q-Q plot shows the dpdfs of single-shell analyses plotted for Holocene ( 3.0 ka, orange) and LGM ( 19.0 ka, blue) intervals. Q-Q plots show that SSTs are uniformly shifted $\sim 2.4^{\circ} \mathrm{C}$ colder and subsurface temperatures are shifted $\sim 2.3^{\circ} \mathrm{C}$ colder during the LGM in comparison with the Holocene. 
Within the eastern Pacific warm pool (EPWP) (Fig. 1C), N. dutertrei at site MD02-2529 show reduced shallow subsurface temperature variability and $\sim 2^{\circ} \mathrm{C}$ cooler average temperatures during the LGM in comparison with the late Holocene (13). N. dutertrei are known to alter their calcification depth, preferring a shallower habitat in places with a well-defined shallow thermocline, such as the EPWP, and a deeper habitat in places such as the EEP (27). The cool LGM subsurface temperatures recorded by $N$. dutertrei are matched by a similar magnitude cooling of the mean surface temperature in the EPWP (discussed below), suggesting that $N$. dutertrei maintained their calcification position near the top of the thermocline. Therefore, a deepening of the thermocline cannot explain reduced shallow subsurface temperature variability at site MD02-2529 and necessitates a reduction of ENSO amplitude, supporting our findings (fig. S16).

Past studies have attempted to characterize the tropical Pacific during the LGM by measuring the WEP-EEP zonal gradient with mixed results $(16,28)$. Our compilation of available SST data in the EEP and WEP reveals spatial heterogeneity in SST cooling during the LGM relative to to- day (table S3). We find that the EPWP and WEP have a similar temperature change $\left(\sim 2.3^{\circ}\right.$ and $2.7^{\circ} \mathrm{C}$, respectively), which suggests that cooling was a function of lower $\mathrm{PCO}_{2}$ and associated radiative forcing in these regions (Fig. 1). In contrast, the EEP cold tongue was only $\sim 1.6^{\circ} \mathrm{C}$ cooler in the LGM. Our single-shell analyses demonstrate that any radiative forcing signal was offset by dynamic changes within the EEP cold tongue, including a deep thermocline $(24,25)$, related changes in upwelling, and reduced ENSO. Overall, this suggests that the western warm pool-cold tongue tropical Pacific zonal SST gradient was reduced.

Our findings do not support previous studies suggesting an inverse relationship between the zonal SST gradient and ENSO variability during the LGM $(11,12)$. Instead, we find weaker ENSO variability when the zonal SST gradient is reduced, consistent with recent modeling results (29). We suggest that an altered thermocline mean state during the LGM reduced ENSO variability by shifting the balance of feedbacks important to ENSO dynamics. Theoretical studies suggest that there is a thermocline mode and an SST mode that give rise to ENSO $(3,5)$. These modes differ in the propagation of subsurface and sur-
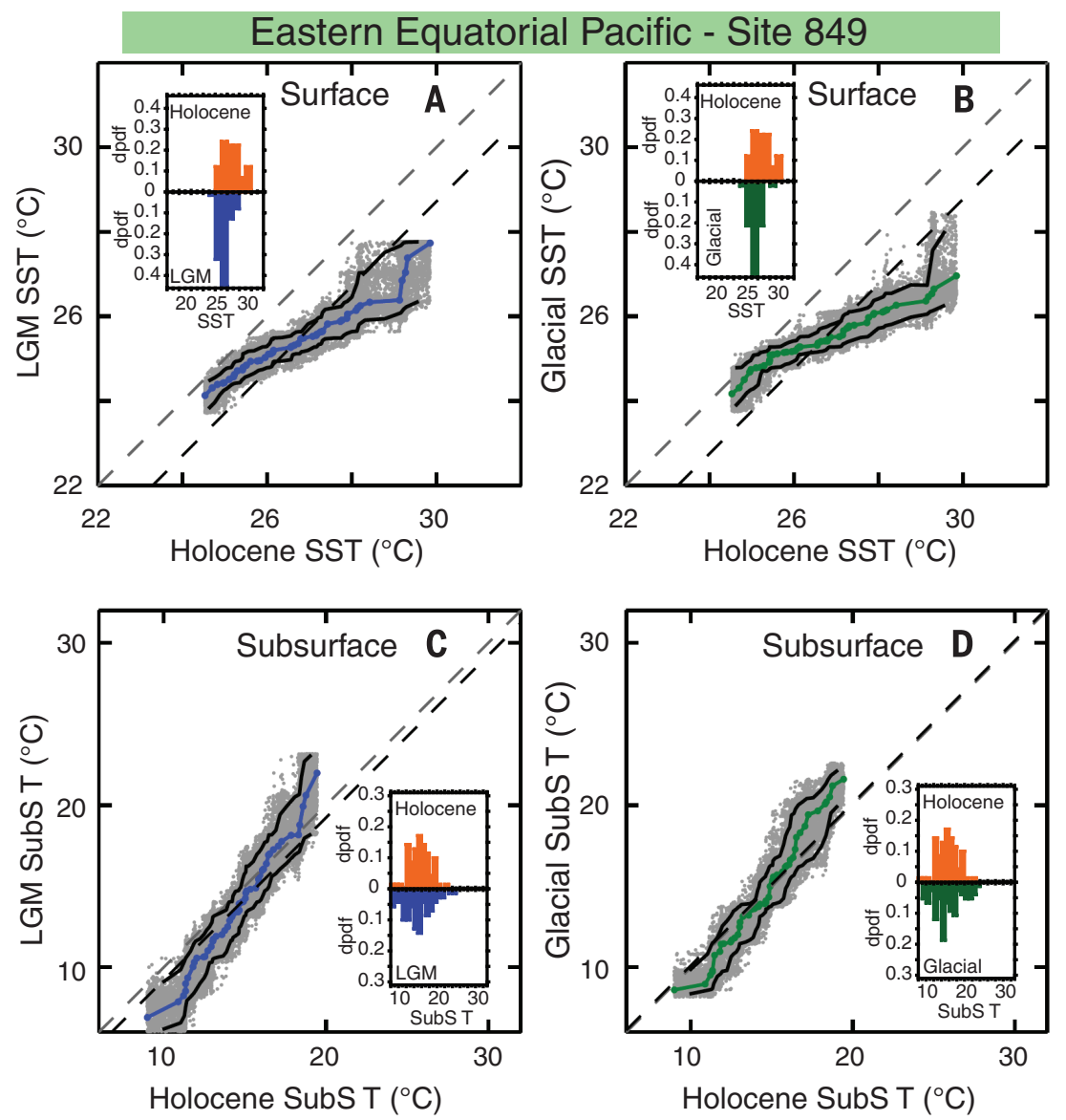

Fig. 4. $\mathrm{Q}-\mathrm{Q}$ plots of EEP temperature variability reconstructed from planktonic foraminifera from the LGM and from one glacial sample. (A and B) Surface temperature variability. (C and $\mathbf{D}$ ) Subsurface temperature variability. The inset within each Q-Q plot shows the dpdfs of single-shell analyses plotted for Holocene ( 2.8 and $\sim 5.6 \mathrm{ka}$, orange), LGM ( 20.3 ka, blue), and glacial ( $21.5 \mathrm{ka}$, green) intervals. Q-Q plots of SSTs show a reduction in ENSO, as demonstrated in Fig. 2. Q-Q plots of subsurface temperatures show greater variability, probably related to a change in the thermocline mean state.

face temperature anomalies, and the balance between these modes changes with mean thermocline depth $(3,5)$. A deep mean thermocline favors the thermocline mode and reduced ENSO amplitude (3). ENSO amplitude is reduced because a deep thermocline inhibits upwelling of anomalous subsurface temperatures, weakening the thermocline feedback and ocean-atmosphere coupling $(4,6,29)$. During the LGM, the zonal SST gradient was reduced, the basin-wide winds were enhanced, and the thermocline was deep $(18,19,24,25)$. With this major change in mean state, the balance of dynamic feedbacks probably changed; one possibility is that this LGM thermocline mean state favored thermocline-mode ENSO behavior and a weakened thermocline feedback that reduced ENSO amplitude.

Although zonal SST gradient reconstructions are often used to infer the tropical mean state and the strength of ocean-atmospheric feedbacks $(11,12,16)$, subsurface temperatures and the equatorial thermocline mean state may more accurately reflect Walker circulation (18) and affect ENSO dynamics (30). Several positive and negative feedbacks determine ENSO behavior (4), and individual feedback strength changes under climate states with different mean thermocline depth and mean wind stress $(3,4,29)$. For example, a deeper thermocline may reduce the strength of the thermocline feedback, thereby reducing ENSO amplitude, but simultaneous changes in the strength of other feedbacks may counteract this effect. Climate models have strong biases in simulating thermocline conditions and tropical upwelling $(5,9)$, and these biases influence the strength and balance of positive and negative feedbacks that determine ENSO behavior. Although model simulations of anthropogenic climate change suggest that the equatorial thermocline will shoal, the effect on the individual feedbacks determining ENSO variability is uncertain (31). The LGM mean state is radically different from future climate projections and thus cannot be directly used to predict future ENSO behavior. However, our results linking observations of the mean state and ENSO variability can be used to test theoretical and numerical models that are pivotal to understanding ENSO behavior in the face of mean state climate changes in the future.

\section{REFERENCES AND NOTES}

1. W. Wang, M. J. McPhaden, J. Phys. Oceanogr. 29, 1812-1831 (1999).

2. W. Wang, M. J. McPhaden, J. Phys. Oceanogr. 30, 2989-3008 (2000).

3. A. V. Fedorov, S. Philander, J. Clim. 14, 3086-3101 (2001).

4. F.-F. Jin, S. T. Kim, L. Bejarano, Geophys. Res. Lett. 33, L23708 (2006).

5. E. Guilyardi et al., Bull. Am. Meteorol. Soc. 90, 325-340 (2009).

6. S.-I. An, F.-F. Jin, J. Clim. 14, 3421-3432 (2001).

7. J. Choi, S.I. An, S.-W. Yeh, Clim. Dyn. 38, 2631-2644 (2012).

8. G. A. Schmidt et al., Clim. Past 10, 221-250 (2014).

9. B. L. Otto-Bliesner et al., Clim. Dyn. 32, 799-815 (2009).

10. J. C. Wit, G.-J. Reichart, S. J. A. Jung, D. Kroon, Paleoceanography 115, PA4220 (2010).

11. A. Koutavas, S. Joanides, Paleoceanography 27, PA4208 (2012).

12. A. Y. Sadekov et al., Nat. Commun. 4, 2692 (2013).

13. G. Leduc, L. Vidal, O. Cartapanis, E. Bard, Paleoceanography 24, PA3202 (2009)

14. S.-I. An, F.-F. Jin, J. Clim. 17, 2399-2412 (2004).

15. J. Boucharel et al., Clim. Dyn. 37, 2045-2065 (2011). 
16. D. W. Lea, J. Clim. 17, 2170-2179 (2004).

17. T. Sagawa, Y. Yokoyama, M. Ikehara, M. Kuwae, Geophys. Res. Lett. 38, L00F02 (2011)

18. P. N. DiNezio et al., Paleoceanography 26, PA3217 (2011)

19. D. H. Andreasen, A. C. Ravelo, Paleoceanography 12, 395-413 (1997).

20. J. Xu, W. Kuhnt, A. Holbourn, M. Regenberg, N. Andersen, Paleoceanography 25, PA4230 (2010).

21. P. Fiedler, L. Talley, Prog. Oceanogr. 69, 143-180 (2006).

22. K. Thirumalai, J. W. Partin, C. S. Jackson, T. M. Quinn, Paleoceanography 28, 401-412 (2013).

23. E. C. Brady, B. L. Otto-Bliesner, J. E. Kay, N. Rosenbloom, J. Clim. 26, 1901-1925 (2013)

24. A. Patrick, R. Thunell, Paleoceanography 12, 649-657 (1997).

25. H. Spero, K. Mielke, E. Kalve, D. Lea, D. Pak, Paleoceanography 18, 1022 (2003).

26. D. Rincón-Martínez, S. Steph, F. Lamy, A. Mix, R. Tiedemann, Mar. Micropaleontol. 79, 24-40 (2011).
27. H. M. Benway, A. C. Mix, B. A. Haley, G. P. Klinkhammer, Paleoceanography 21, PA3008 (2006).

28. A. Koutavas, J. Lynch-Stieglitz, T. M. Marchitto Jr., J. P. Sachs, Science 297, 226-230 (2002)

29. G. E. Manucharyan, A. V. Fedorov, J. Clim. 27, 5836-5850 (2014)

30. Z.-Z. Hu et al., J. Clim. 26, 2601-2613 (2013).

31. M. Collins et al., Nat. Geosci. 3, 391-397 (2010).

32. N. A. Rayner et al., J. Geophys. Res. 108, 4407 (2003).

\section{ACKNOWLEDGMENTS}

We thank P. DiNezio, A. Fedorov, B. Hönisch, G. Manucharyan, A. Moore, A. Paytan, J. Zachos, and two anonymous reviewers for comments on the manuscript. R. Franks, E. Chen, J. Hourigan, and N. Movshovitz provided analytical support. For this research, we used samples provided by the Integrated Ocean Drilling Program (IODP). Funding for this research was provided by NSF grant OCE-1204254 (A.C.R.), the
Achievement Rewards for College Scientists Foundation (H.L.F.) and the Schlanger Fellowship (H.L.F), which is part of the NSF-sponsored U.S. Science Support Program for IODP that is administered by the Consortium for Ocean Leadership. Our data are deposited at the National Oceanic and Atmospheric Administration National Climatic Data Center and Pangaea.

\section{SUPPLEMENTARY MATERIALS}

www.sciencemag.org/content/347/6219/255/suppl/DC1

Materials and Methods

Supplementary Text

Figs. S1 to S17

Tables S1 to S3

References (33-70)

7 July 2014; accepted 11 December 2014

10.1126/science.1258437

\section{PALEOECOLOGY}

\section{Linked canopy, climate, and faunal change in the Cenozoic of Patagonia}

Regan E. Dunn, ${ }^{1 *}$ Caroline A. E. Strömberg, ${ }^{1}$ Richard H. Madden, ${ }^{2}$ Matthew J. Kohn, ${ }^{3}$ Alfredo A. Carlini ${ }^{4}$

Vegetation structure is a key determinant of ecosystems and ecosystem function, but paleoecological techniques to quantify it are lacking. We present a method for reconstructing leaf area index (LAI) based on light-dependent morphology of leaf epidermal cells and phytoliths derived from them. Using this proxy, we reconstruct LAl for the Cenozoic (49 million to 11 million years ago) of middle-latitude Patagonia. Our record shows that dense forests opened up by the late Eocene; open forests and shrubland habitats then fluctuated, with a brief middle-Miocene regreening period. Furthermore, endemic herbivorous mammals show accelerated tooth crown height evolution during open, yet relatively grass-free, shrubland habitat intervals. Our Patagonian LAI record provides a high-resolution, sensitive tool with which to dissect terrestrial ecosystem response to changing Southern Ocean conditions during the Cenozoic.

1

egetation structure-the degree of canopy openness-is a fundamental aspect of ecosystems, influencing productivity, hydrological and carbon cycling, erosion, and composition of faunal communities $(1,2)$.
However, methods to quantify ancient vegetation structure have eluded paleoecologists. Here, we present a method with which to reconstruct vegetation openness, specifically leaf area index $\left[\mathrm{LAI}=\right.$ foliage area $\left(\mathrm{m}^{2}\right) /$ ground area $\left.\left(\mathrm{m}^{2}\right)\right]$, using the morphology of leaf epidermal cells preserved as phytoliths (plant biosilica) (Fig. 1). LAI quantifies vegetation structure in ecological and climate modeling studies $(1,3)$. In modern ecosystems, LAI relates primarily to soil moisture (4), by which vegetation becomes more closed with increasing soil water availability; ultimately, soil moisture is determined by temperature, precipitation, and atmospheric partial pressure of $\mathrm{CO}_{2}$ $\left(P_{\mathrm{CO}_{2}}\right)(4,5)$. Disturbance in the form of fire and herbivory can offset this relationship, resulting in open habitats in areas with relatively high rainfall (6).

Using this paleobotanical archive, we reconstructed a LAI record for the middle Cenozoic [49 million to 11 million years ago $(\mathrm{Ma})]$ of Patagonia to test predictions about vegetation

${ }^{1}$ Department of Biology and Burke Museum of Natural History and Culture, University of Washington, Seattle, WA 98195, USA. ${ }^{2}$ Department of Organismal Biology and Anatomy, University of Chicago, Chicago, IL 60637, USA

${ }^{3}$ Department of Geosciences, Boise State University, Boise, ID 83725, USA. ${ }^{4}$ Paleontología de Vertebrados, Universidad Nacional de La Plata, Consejo Nacional de Investigaciones Científicas y Técnicas (CONICET), La Plata, Argentina. *Corresponding author. E-mail: dunnr@u.washington.edu
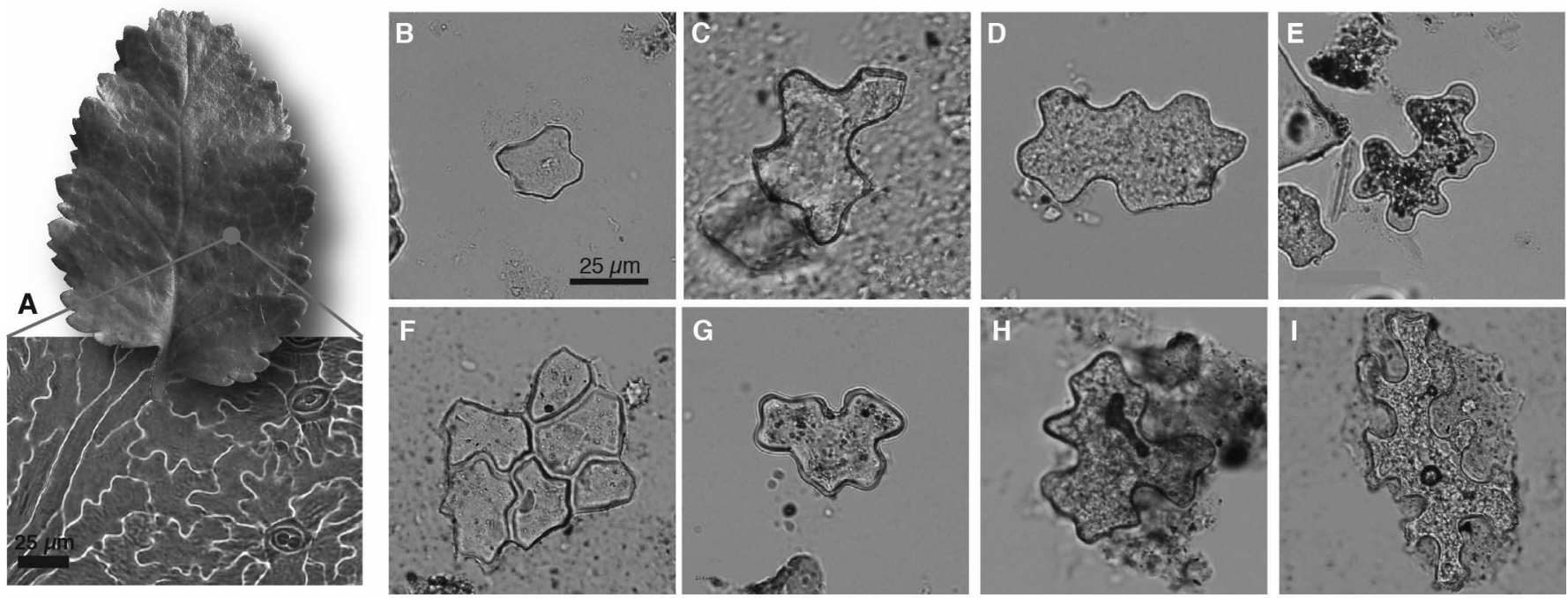

Fig. 1. Leaf epidermis and examples of epidermal phytoliths. (A) Nothofagus leaf and epidermis. (B to E) Fossil phytoliths from Patagonia. (F to I) Modern soil phytoliths from Costa Rica. 


\section{Reduced EI Niño-Southern Oscillation during the Last Glacial} Maximum

Heather L. Ford et al.

Science 347, 255 (2015);

DOI: $10.1126 /$ science. 1258437

This copy is for your personal, non-commercial use only.

If you wish to distribute this article to others, you can order high-quality copies for your colleagues, clients, or customers by clicking here.

Permission to republish or repurpose articles or portions of articles can be obtained by following the guidelines here.

The following resources related to this article are available online at www.sciencemag.org (this information is current as of January 20, 2015 ):

Updated information and services, including high-resolution figures, can be found in the online version of this article at:

http://www.sciencemag.org/content/347/6219/255.full.html

Supporting Online Material can be found at:

http://www.sciencemag.org/content/suppl/2015/01/14/347.6219.255.DC1.html

This article cites 67 articles, 7 of which can be accessed free:

http://www.sciencemag.org/content/347/6219/255.full.html\#ref-list-1

This article appears in the following subject collections:

Geochemistry, Geophysics

http://www.sciencemag.org/cgi/collection/geochem_phys 